\title{
The relationship of cultural intelligence with self-government of future teachers in the educational environment of a multi-ethnic region (on the example of the Khabarovsk Territory)
}

\author{
E.V. Kulesh ${ }^{1 *}$, L.F. Vyaznikova ${ }^{2}$, and C.I. Vorobyeva ${ }^{3}$ \\ ${ }^{1}$ Pacific National University, Khabarovsk, Russia \\ ${ }^{2}$ Pacific National University, Khabarovsk, Russia \\ ${ }^{3}$ Pacific National University, Khabarovsk, Russia
}

\begin{abstract}
The paper presents the results of a study on the study of the relationship between self-government and the cultural intelligence of teachers in the educational environment of the multi-ethnic Khabarovsk Territory. The presented pedagogical system of interconnection based on the principles of using the cluster approach in the interaction of institutions of preschool, general, secondary vocational and higher education in the exchange of experience and the dissemination of best practices.
\end{abstract}

\section{A problem statement}

Today, teachers of educational institutions will have to work in a rapidly and dramatically changing environment of uncertainty of professional activity, where the teacher's personal resources come to the fore as one of the conditions for effective interaction in the multiethnic educational environment of the region. Against this background, it becomes necessary to search for optimal ways of human adaptation to the changing conditions of social reality. To train a new generation of specialists, effective forms and methods of organizing the educational process are needed that can reveal the potential capabilities of students $[1 ; 2]$. It is even more difficult to do this when representatives of different ethnic groups, with different mentality and cultural traditions meet. And here, it is obvious that the tasks become more complicated, since the success of the student's adaptation depends on what kind of psychological environment will be created in which the subjects of educational activity will interact, which is the foundation of his further successful learning and development [3].

\footnotetext{
*Corresponding author: ipcs-profped@yandex.ru
} 


\subsection{The objective of the work}

The theoretical methods used are based on the analysis of the study of psychological and pedagogical literature; description of the cluster approach in the organization of teaching activities. The following diagnostic techniques were used as empirical methods: "Extended scale of cultural intelligence" by G.U. Soldatova [4]; "The ability of personality selfgovernment" N.M. Peisakhova [5]; "The scale of basic beliefs" as adapted by M.A. Padun and A.V. Kotelnikova [6]. To determine the presence of a relationship between the studied indicators, we conducted a correlation analysis using the Pearson coefficient. The study involved 150 students, aged 17 to 25 years old, studying in a multi-ethnic educational space and living in the city of Khabarovsk and the city of Nikolaevsk-on-Amur, Khabarovsk Territory.

\section{Materials and the results of the research}

Analyze and reveal the specifics of the relationship of cultural intelligence with the selfgovernment of teachers in the educational space of a multi-ethnic region, which is a condition for the formation and development of ethnospecific features and qualities of a person. Such as a representative of a specific ethnic group where the process of assimilation and translation of ethno-ethnic and other humanistic values by a subject taking into account regional specifics is carried out within the boundaries (on the example of the Khabarovsk territory).

In order to implement the mechanisms and forms of continuous pedagogical education within the framework of the requirements of the professional standard "Teacher," the regional innovation complex "Model of ethnocultural development of subjects of educational activity in the multi-ethnic region (Khabarovsk Territory)". This is currently base on the Resource Center of the Pacific State University, on the problem of developing the cultural intelligence of students.

The model of implementation of innovation activity of the complex based on the principles of interaction of institutions of preschool, general, secondary vocational and higher education, which includes exchange of experience and dissemination of best practices on development of ethnocultural competence and linguistic culture in the territory of the region [7]. Separately, the innovation project implements two strategic directions for the formation of the language culture of the student's personality.

The first direction of the complex focused on teaching the Russian language as a state child-informer in those educational institutions of the region that experience learning difficulties due to poor adaptation to a different cultural environment, where there is a complex mastery of the Russian language and communication difficulties. The second direction of the complex aimed at preserving and popularizing native languages, including educational institutions from the villages of the municipal Nikolaevsk-on-Amur and Nanai districts of the Khabarovsk Territory (using the example of the Ulch and Nanai ethnos).

In this context, the principle of the protection of national cultures by the education system is an important principle and traditions in a multicultural state. The education system provides the person with knowledge, allowing him to integrate into the world of socio-cultural relations, predict the further development of this world and the main thing to find his place in German. This is a specific feature of the cultural and educational space of a multi-ethnic region is its involvement in ethnic processes characterized by interaction, dialogue, integration of ethnic cultures. We agree with the opinion of I.S. Karabulatova that in the conditions of multi-ethnic contacts, the individual, gaining an ethnic identity, also gains cultural historical memory, deep historical and cultural roots, connection with tradition, a sense of historical and intergenerational continuity, continuity and sustainability 
[3]. Against this background, within the framework of the cultural and educational space, ethnic characteristics, value orientations, principles and stereotypes of the behavior of people and representatives of various ethnic communities formed. In this regard, the cultural and educational space of a multi-ethnic region is a condition for the formation and development of ethnospecific features and qualities of a person as a representative of a particular ethnic group. Within its boundaries, the process of assimilation and translation by the subject of ethno-national and other humanistic values carried out, taking into account regional specifics [8].

Practice has shown that the organization of cluster interaction in the cultural and educational space of a multi-ethnic region requires combining efforts, primarily teachers, with developed cultural intelligence and the ability of self-government. Note that in English, the word "cluster" means "bundle," "bunch," "group," "grow bundles," "concentration." The success of the developed strategy depends on the extent to which the goals of teachers, children, parents are combined into one, the goal and tasks are agreed, aspects of personal meaning that are attractive to all subjects are found. By educational cluster, we mean such a system of network interaction of educational organizations. They aimed at improving the quality of the educational process in the interests of development of priority socio-economic sectors of the region responsible for efficiency and quality of solving a certain range of tasks at a specific stage of activities of subjects for the development of the younger generation [4].

Let us turn to the results of an empirical study. The sample consisted of 150 students, aged 17 to 25, studying at the Nikolaev-on-Amur Industrial and Humanities College, at the Pedagogical College and Pedagogical Institute of the Pacific State University of the Khabarovsk Territory.

At the initial stage of the study, the question arose about the features of the manifestation of the cultural intelligence of the personality of future teachers. In our study, we focused on the point of view of G.U. Soldatova, who believes that cultural intelligence is a certain type of social intelligence, which aimed at a specific social context determined by some cultural characteristics of the person. In other words, cultural intelligence can defined as the ability of a person to adapt in a new cultural environment [9]. It is important to note that cultural intelligence includes cognitive, metacognitive, motivational and behavioral components, covering the main levels of interpersonal interaction and providing an integrative approach to solving cross-cultural situations characterized by complexity, uncertainty, diversity of cultural dimensions, and adaptation to them.

Let us turn to the results of the diagnostic study according to the methodology "Extended Scale of Cultural Intelligence" by G.U. Soldatova, presented in Table 1.

Table 1. Average values of cultural intelligence of the students.

\begin{tabular}{|l|c|c|c|c|c|c|}
\hline \multirow{2}{*}{ Indicators } & \multicolumn{2}{|c|}{ NPGT } & \multicolumn{2}{c|}{ KhPG } & \multicolumn{2}{c|}{ PNU } \\
\cline { 2 - 7 } & $\begin{array}{c}\text { Quantity } \\
\text { elections }\end{array}$ & $\%$ & $\begin{array}{c}\text { Quantity } \\
\text { elections }\end{array}$ & $\%$ & $\begin{array}{c}\text { Quantity } \\
\text { elections }\end{array}$ & $\%$ \\
\hline Motivational CI & 1 & 10 & 3 & 21,4 & 1 & 20 \\
\hline Cognitive CI & 4 & 40 & 3 & 21,4 & - & - \\
\hline Metacognitive CI & 2 & 20 & - & - & 2 & 40 \\
\hline Behavioural CI & 2 & 20 & 7 & 50 & - & - \\
\hline General CI & 1 & 10 & 1 & 7,1 & 2 & 40 \\
\hline
\end{tabular}

Analysis of the results showed that in students of the College of Education, a metacognitive indicator of cultural intelligence in the middle range of values was not reveal, which may indicate a lack of ability of students to reflect about their own ethnicity and cultural affiliation, as well as the impossibility of predicting behavior in a 
situation of intercultural interaction. The students of the Industrial and Humanities College showed a low level of motivational indicator of cultural intelligence, which may indicate their poor readiness to learn a new culture. In students of the university, we identified the absence of a cognitive and behavioral component, which may indicate the absence or low level of knowledge of customs, values, norms of human activity in various cultures, as well as the absence of verbal and non-verbal forms of behavior that would be suitable for contact with persons from other cultures.

Next, we turn to the results of a diagnostic study on the methodology "Personality Self-Government Ability" by N.M. Peisakhov, which presented in Table 2. Of particular urgency in this context are the works of this author, who considers self-government in the context of the ability of a person to predict the future results of his activities: determine long-range goals and plan his actions and actions, put forward quality assessment criteria to extract information about the progress of the self-government process and amend it, which is undoubtedly creative. Obviously, the ability of selfgovernment is a process in which the subject himself determines the problem and develops the optimal tactics and strategy of his activity to solve various problems in life, realizing the creative style as a kind of author's position. In this sense, the training of a new generation of specialists requires effective forms and methods of organizing the educational process that can reveal the potential opportunities of students.

Table 2. Average Student Self-Government Abilities.

\begin{tabular}{|l|c|c|c|c|c|c|}
\hline \multirow{2}{*}{\multicolumn{1}{|c|}{ Indicators }} & \multicolumn{2}{|c|}{ NPGT } & \multicolumn{2}{c|}{ KhPG } & \multicolumn{2}{c|}{ PNU } \\
\cline { 2 - 7 } & $\begin{array}{l}\text { Quantity } \\
\text { elections }\end{array}$ & $\%$ & $\begin{array}{c}\text { Quantity } \\
\text { elections }\end{array}$ & $\%$ & $\begin{array}{c}\text { Quantity } \\
\text { elections }\end{array}$ & $\%$ \\
\hline $\begin{array}{l}\text { Analysis of } \\
\text { contradictions }\end{array}$ & 2 & 0,8 & 29 & 16 & 25 & 11,1 \\
\hline Forecasting & 24 & 10,6 & 25 & 13,8 & 22 & 9,7 \\
\hline Goal setting & 32 & 14,2 & 2 & 1,1 & 34 & 15,1 \\
\hline Planning & 30 & 13,3 & 23 & 12,7 & 23 & 10,2 \\
\hline $\begin{array}{l}\text { Criterion for evaluation } \\
\text { of quality }\end{array}$ & 24 & 10,6 & 18 & 9,9 & 26 & 11,5 \\
\hline Decision-making & 26 & 11,5 & 16 & 8,8 & 17 & 7,5 \\
\hline Self-checking & 32 & 14,2 & 28 & 15,4 & 26 & 11,5 \\
\hline Correction & 27 & 12 & 24 & 13,2 & 28 & 12,4 \\
\hline General SGA & 28 & 12,4 & 16 & 8,8 & 24 & 10,6 \\
\hline
\end{tabular}

When analyzing the obtained indicators of individual self-government ability, we revealed that among students of an industrial and Humanities College, such an indicator as analysis of contradictions or orientation in a situation developed, which can indicate the complexity of students to detect contradictions in external conditions and create a subjective model of the current situation. Among students studying at a teacher training college, a low ability to target revealed, which indicates a weak ability to form models of the desired future and goals, while students at a higher educational institution showed those within the average values.

Further, a significant aspect of the study was the identification of the specifics of the beliefs of future educators, since the constantly changing reality leads people to interpret what is happening in such a way as to maintain the stability of the surrounding picture of the world and provide the necessary support for achieving a sense of security. For the study of dominant personality beliefs, we used the technique in the adaptation of Padun M.A. and A.V. Kotelnikova "Scale of Basic Beliefs". 
Table 3. Average Student Base Beliefs.

\begin{tabular}{|l|c|c|c|c|c|c|}
\hline \multirow{2}{*}{ Indicators } & \multicolumn{2}{|c|}{ NPGT } & \multicolumn{2}{c|}{ KhPG } & \multicolumn{2}{c|}{ PNU } \\
\cline { 2 - 7 } & $\begin{array}{c}\text { Quantity } \\
\text { elections }\end{array}$ & $\%$ & $\begin{array}{c}\text { Quantity } \\
\text { elections }\end{array}$ & $\%$ & $\begin{array}{c}\text { Quantity } \\
\text { elections }\end{array}$ & $\%$ \\
\hline Self-image & 33 & 22,2 & 27 & 14,4 & 41 & 24,7 \\
\hline $\begin{array}{l}\text { Benevolence of the } \\
\text { world around him }\end{array}$ & 22 & 14,9 & 31 & 16,6 & 30 & 18 \\
\hline Justice & 33 & 22,2 & 28 & 15 & 32 & 19,3 \\
\hline Luck & 31 & 20,9 & 72 & 38,5 & 32 & 19,3 \\
\hline $\begin{array}{l}\text { Beliefs about } \\
\text { control }\end{array}$ & 29 & 19,6 & 29 & 15,5 & 31 & 18,7 \\
\hline
\end{tabular}

In the study, basic beliefs defined by us as the stable ideas of the individual about the world and about himself, influencing the thinking, emotional states and behavior of a person. Such a structure reflect in five sub-scales and consists of the individual's internal ideas about the world around him, his own self, as well as the ways of interaction between the world and me. The basic belief of benevolence - the hostility of the surrounding world reflects the individual's ideas about the safe ability to trust the surrounding world and represented by the "benevolence of the surrounding world" sub-scale. The basic belief about the justice of the world around us represents the individual's beliefs about the principles of the distribution of luck and misfortune and contains two categories: "justice" and "beliefs about control." The indicators of two sub-scales of the questionnaire also characterize the basic belief about the value and significance of one's own self: "image of self" and "luck." Thanks to these measurements, we discover common points of contact between ethnocultural traditions and global general cultural values, based on a stable spiritual tradition [10]. The results of the diagnostic study on the Basis Belief Scale methodology presented in Table 3.

When we analyzing the obtained indicators, we determined that two types of basic beliefs prevail among students of a pedagogical college. The first is the basic belief "image of self," the second type of beliefs is "justice"; students of the Industrial and Humanities College dominated by the basic belief of "benevolence of the world around them"; students of the university have the belief "image of the self".

Note that in a multiethnic educational environment, due to the need to enter the sphere of interaction between cultures, teachers, including the future, will be characterized by certain strategies of intercultural interaction that reflect the characteristics of his behavior $[11 ; 12]$. As a result, this is associated with the processes of self-knowledge and selfdevelopment, which can contribute to the understanding of representatives of other cultures in the context of the ethnic diversity of the contingent of the educational institution.

In order to take a deeper look at this issue, let us turn to the concept of interaction. In our opinion, the key is the definition of V.E. Kemerova, interaction is the concept that reflects the relationship between various objects, also characterizes various forms of human existence, human activity and cognition $[13 ; 14]$. Direct communication between human individuals can be an example of interaction in public life. So, the interconnection of the subjects of the pedagogical process is an integrative and multifunctional factor of their mutual self-development, is an example of the pedagogical interaction of students and teachers [15].

It is precisely this that is capable of influencing the purposeful, progressive and productive development of schoolchildren and teachers. As well as strengthening their community, subject to its systematic enrichment and development as a phenomenon and process. 
The essence of the influence of the strategies of intercultural interaction chosen by the teacher on the personal self-development of his subjects. This is due to the emergence in the process of exchange between them of cognitive, volitional, emotional, value and other potentials of psychological and pedagogical phenomena and effects that determine the nature and degree of the influence under consideration [16].

The study of the essence and specifics of the strategies of intercultural interaction chosen by the teacher shows that there are a variants of the strategies of social interaction and have its main features, characteristic features. At the same time realize in the process of their implementation a specific goal, but extremely important for the existence and formation of an individual, this is the promotion of self-development personality $[17 ; 18]$.

The specificity of the chosen strategies of intercultural interaction between the teacher and the student-migrant is that in the course of its implementation, the self-development of partners occurs as interconnected, which is largely facilitate by the peculiar phenomena and effects arising in this case [19].

The results of a diagnostic study by the method of E.V. Falunina's "Strategy of intercultural interaction in a multicultural educational environment" showed that future teachers in the majority choose such a strategy of interaction as "consolidation", which characterizes them as people who know how to enter the world of another culture, while maintaining their cultural identity (see table 4).

Table 4. Average indicators of strategies for intercultural interaction in a multicultural educational environment.

\begin{tabular}{|l|c|c|c|c|c|c|}
\hline \multirow{2}{*}{ Indicators } & \multicolumn{2}{|c|}{ NPGT } & \multicolumn{2}{c|}{ KhPG } & \multicolumn{2}{c|}{ PNU } \\
\cline { 2 - 7 } & $\begin{array}{c}\text { Quantity } \\
\text { elections }\end{array}$ & $\mathbf{\%}$ & $\begin{array}{c}\text { Quantity } \\
\text { elections }\end{array}$ & $\%$ & $\begin{array}{c}\text { Quantity } \\
\text { elections }\end{array}$ & $\%$ \\
\hline Consolidation & 21 & 42 & 25 & 50 & 20 & 40 \\
\hline Integration & 15 & 30 & 11 & 22 & 14 & 28 \\
\hline Marginality & 6 & 12 & 6 & 12 & 6 & 12 \\
\hline Assimilation & 4 & 8 & 4 & 8 & 6 & 12 \\
\hline Separatism & 4 & 8 & 4 & 8 & 4 & 8 \\
\hline
\end{tabular}

Further, using the correlation analysis according to the Pearson coefficient, we identified the relationship in a group of university students between the metacognitive indicator of cultural intelligence, the ability of personality self-government and the basic beliefs "goodwill of the world", "self-image" and "luck" and such a strategy of intercultural interaction as "consolidation" (at $\mathrm{r}=0.70$ ). It speaks about a sufficiently high level of awareness and ability to form models of interaction with representatives of other nationalities, as well as the presence of contradictions between their culture and other cultures, since they often prefer to be convinced of the superiority of their culture.

Among students of a pedagogical college, a relationship was revealed between selfgovernment and motivational cultural intelligence with such basic beliefs as "the benevolence of the surrounding world" and "fairness" and such a strategy of intercultural interaction as "consolidation" (at $r=0.60$ ). It speaks about the readiness of students to create a model of the current situation when detecting contradictions in the external multicultural environment and to rely on the benevolence of the outside world when resolving it. In addition, this may indicate that students have the ability to direct their attention to changing the system of individual self-government in a multi-ethnic educational environment in order to prevent the formation of discriminatory forms of interethnic relations in the educational space.

The students of the industrial and humanitarian college showed a medium level of interconnection between personality self-government, scales of cultural intelligence and basic beliefs "belief in control", "goodwill of the surrounding world", "luck" and such a 
strategy of intercultural interaction as "consolidation" (at $r=0,55)$. It speaks about the possibility of abandoning one's own ethnic identity while moving towards one's goals.

\section{Conclusions}

Thus, the results of theoretical and empirical analysis on the indicated problem of study made it possible to determine that there are features in the relationship of cultural intelligence with the self-government of future teachers, the manifestation of which will depend on the different content of beliefs in the cultural and educational space of the multiethnic region. These characteristics can manifested in relation to representatives of their own and other ethnic groups, in the presence of social distance and with different levels of readiness to interact with people of different nationalities. As a result, the professional education of future teachers requires the search for new approaches to the educational process in order to develop the creative potential and socio-cultural adaptability of students who are representatives of different cultures within professional educational institutions with a multi-ethnic educational environment.

One of the possible means of developing personal self-government of future teachers in a multicultural educational environment is the implementation of the course of the program "From self-determination to self-government" using the technology of theoretical and training classes [20]. The course includes sections of thematic blocks consisting of selfknowledge, which involves the study of the requirements for a teacher. Planning, which consists of determining the goal and objectives, developing a program of self-development, choosing personal rules of behavior, forms, means, methods and methods of solving problems in working on themselves and self-control and self-correction in intercultural communication, which includes reflexion of activities involving direct practical activity on the basis of educational institutions of the region.

Therefore, it can conclude that the educational space of the Khabarovsk Territory demonstrates one of the models of integration of ethnic groups inhabiting this territory and representing a certain cultural significance that distinguishes this territory from others. In the light of the policy of regionalization of the regional education system, we have determined that the management of the process of professional self-development is effective. If it based on the principles of social partnership within an educational cluster, which allows creating a kind of educational network that allows achieving the necessary effect due to the specific contribution of each organization to the achievement of results, to benefit not only partnership participants, but also educational actors, while maintaining their differences. The results of the study can use to create a program of psychological and pedagogical support for students for the development of intercultural communication in the multi-ethnic educational environment of the institution. Which as a result will allow students to realize the new quality of their social position; to master the methods and techniques of organizing educational and extracurricular activities, to understand the necessary professional and personal qualities, to adjust their own plans for the period of study in a professional institution.

\section{References}

1. N.A. Astashova, S.K. Bondyreva. A.P. Smantser, Development of the axiosphere of the future teacher in the dialogue space of modern education. Education and Science, 20 (7), 32-67 (2018)

2. A.B. Bagdasarova, Cultural and educational space in a multi-ethnic macro-region. News of universities. North Caucasus region. Social Sciences, 2, 9-13 (2008) 
3. L.F. Vyaznikova, Mentality in the axiological space of society. Russia in the world community: the semantic space of the dialogue of cultures: materials of the International Forum "Eastern Vector of Migration Processes: Dialogue with Russian Culture, Khabarovsk, November 16-17, 89-91 (2016)

4. I.S. Karabulatova, The transformation of the mentality of the modern Russian multiethnic region as a phenomenon of tolerance. Humanitarian problems of migration: socio-legal aspects of the adaptation of compatriots in the Tyumen region, 1, 31 (2006)

5. L.D. Stolyarenko, Fundamentals of Psychology. (Rostov-on-Don: Phoenix, 1997)

6. M. Padun, N. Tarabrina, Mental trauma and basic cognitive schemes. Moscow Psychotherapeutic Journal, 1, 121-141 (2003)

7. V.A. Yasvin, Educational environment: from modeling to design. (Moscow: Smysl, 2001)

8. I. Ignatova, "Tufts" and "clusters" of management. School management, 24, 17-20 (2009)

9. G.U. Soldatova, S.V. Chigarkova, E.V. Kulesh, M.Yu. Tikhomirov, Ethno-social and personality predictors of the direction of intercultural communication among residents of Russian cities with different ethnic composition of the population. Psychological research (electronic journal), 11 (62) (2018). Available at: http://psystudy.ru/index.php/num/2018v11n62/1650-soldatova62.html

10. K.M. Gozhev, Anthropology of education and social conflict. (St. Petersburg: Publisher, 2004)

11. L.I. Lurie, Modeling regional educational systems. (Moscow: Gardariki, 2006)

12. T.V. Poshtareva, Features of education in an ethnically diverse environment. Secondary vocational education, 6, 59 (2008)

13. E.V. Safarova, Interaction as an interdisciplinary scientific category: an overview of approaches to understanding the essence. Modern science-intensive technologies, 10-1, 170-174 (2019)

14. Yu.S. Davydov, World in multiethnic Russia through languages, education, culture. Professional Issue, 7-9 (2008).

15. V.I. Slobodchikov, Anthropology of education. School technologies. 3, 3-8 (2008)

16. V.N. Pavlenko, Acculturation strategies and models of identity transformation among migrants. Psychology of refugees and forced migrants: experience of research and practical work. 25-39 (2001)

17. K. Ward, The ABC of Acculturation. Psychology and Culture. 657-709 (2003)

18. G.K. Triandis, Culture and social behavior. Moscow: Forum. 135-143 (2007)

19. E.V. Falunina, The problem of studying actual strategies of interaction of cultures in modern education. Problems of socio-economic development of Siberia. 4 (6), 115-117 (2011)

20. E.V. Kulesh, Theoretical training sessions at the stage of students' adaptation in secondary and higher educational institutions "From self-determination to selfgovernment”. (Khabarovsk: Publishing House FESHU, 2011) 